\title{
Indução de resistência em feijoeiro a mancha angular por extratos de micélio de Pycnoporus sanguineus
}

\author{
Clair Aparecida Viecelli ${ }^{1}$; José Renato Stangarlin¹; Odair José Kuhn ${ }^{1}$ \& Kátia Regina Freitas Schwan-Estrada ${ }^{2}$
}

${ }^{1}$ Centro de Ciências Agrárias, Universidade Estadual do Oeste do Paraná (Unioeste), C.P. 91, CEP 85960-000, Marechal Cândido Rondon/PR, e-mail: clairviecelli@ hotmail.com; ${ }^{2}$ Departamento de Agronomia, Universidade Estadual de Maringá (UEM), Av. Colombo 5790, CEP 87020900, Maringá/PR.

Autor para correspondência: José Renato Stangarlin

Data de chegada: 31/03/2008. Aceito para publicação em: 17/11/2008.

\section{RESUMO}

Viecelli, C.A.; Stangarlin, J.R.; Kuhn, O.J.; Schwan-Estrada, K.R.F. Indução de resistência em feijoeiro a mancha angular por extratos de micélio de Pycnoporus sanguineus. Summa Phytopathologica, v.36, n.1, p.73-80, 2010.

O feijoeiro (Phaseolus vulgaris L.) está entre as principais culturas da agricultura nacional e pode ser afetada por várias doenças, como a mancha angular causada por Pseudocercospora griseola. Com o objetivo de desenvolver métodos alternativos ao químico para o controle desta doença, verificou-se o potencial de extratos de micélio de Pycnoporus sanguineus para atividade antimicrobiana in vitro contra $P$. griseola e para indução de resistência e ativação de enzimas de defesa em feijoeiro, como peroxidase, polifenoloxidase e $\beta-1,3$ glucanase, além de sua influência nos teores de proteínas e clorofilas. Os experimentos in vitro e em casa de vegetação foram constituídos pelos extratos de micélio de P. sanguineus e dos controles água, acibenzolar-S-metil (ASM: $75 \mathrm{mg}$ i.a./L) e fungicida azoxystrobin (40 mg i.a./L). In vitro o extrato de micélio apresentou efeito sobre o crescimento micelial, a esporulação e a germinação de esporos de $P$. griseola. In vivo a severidade foi reduzida em $93 \%$ e $50 \%$ em casa de vegetação e a campo respectivamente, em relação ao controle água. A atividade das enzimas peroxidase e polifenoloxidase e os teores de proteínas e clorofilas foram maiores nas plantas tratadas com o extrato. Estes resultados indicam a eficiência de P. sanguineus para o controle alternativo da mancha angular do feijoeiro.

Palavras-chave adicionais: Phaseolus vulgaris, Pseudocercospora griseola, Phaeoisariopsis griseola, controle alternativo.

\section{ABSTRACT}

Viecelli, C.A.; Stangarlin, J.R.; Kuhn, O.J.; Schwan-Estrada, K.R.F. Resistance induction in bean plants against angular leaf spot by extracts from Pycnoporus sanguineus mycelium. Summa Phytopathologica, v.36, n.1, p.73-80, 2010.

Angular leaf spot, caused by the fungus Pseudocercospora griseola, is a major disease of common bean (Phaseolus vulgaris L.) in Brazil. The objective of this research was to develop an alternative method for controlling this disease based on an aqueous extract of Pycnoporus sanguineus mycelium. It was evaluated the antimicrobial activity of the aqueous extract against $P$. griseola as well as its activity of resistance induction against angular leaf spot. The role of the plant defense enzymes peroxidase, polyphenol oxidase and $\beta-1,3$-glucanase, and the proteins and chlorophyll content was investigated. The experiments in vitro and in greenhouse used extracts from mycelium of $P$. sanguineus and water, Acibenzolar-S-methyl (ASM: $75 \mathrm{mg} / \mathrm{L}$ ) and the fungicide azoxystrobin $(40 \mathrm{mg} / \mathrm{L})$ were the control treatments. In vitro, the extract of mycelium inhibited the mycelial growth as well as the sporulation and conidia germination of $P$. griseola. However severity was reduced in $93 \%$ and $50 \%$ in greenhouse and field respectively. The activities of peroxidase, polyphenol oxidase and the content of proteins and chlorophylls had an increment in plants treated with extract. These results indicate the potential of $P$. sanguineus for alternative control of the angular leaf spot in bean.

Keywords: Phaseolus vulgaris, Pseudocercospora griseola, Phaeoisariopsis griseola, alternative control.

A cultura do feijoeiro (Phaseolus vulgaris L.) pode ser afetada por mais de 300 doenças causadas por vírus, bactérias, fungos e nematóides. Com relação à parte aérea da planta, o fungo hemibiotrófico Pseudocercospora griseola (Sacc.) Crous \& Braun (sin. Phaeoisariopsis griseola (Sacc.) Ferraris) agente causal da mancha angular, representa um dos principais patógenos fúngicos do feijoeiro, manifestando-se no caule, folhas e vagem da planta (4). Tradicionalmente o controle da mancha angular tem sido feito com o emprego de cultivares resistentes, sementes livres de patógenos e aplicação de fungicidas. Este último, a curto prazo, tem suas vantagens mas a longo prazo pode causar problemas devido aos resíduos acumulados nos produtos e no ambiente (13), sendo necessário desta forma desenvolver métodos alternativos de controle de doenças como a indução de resistência em plantas usando produtos naturais (19).

A indução de resistência em plantas envolve a ativação de mecanismos de defesa latentes existentes nas plantas em resposta ao tratamento com agentes eliciadores, os quais são capazes de ativar mecanismos de defesa na planta, protegendo-a contra infecções subseqüentes por patógenos (22). Entre os eliciadores não convencionais podem-se incluir os extratos de plantas medicinais e 
óleos essenciais $(19 ; 20)$, bem como os extratos obtidos de cogumelos (9).

Entre os basidiomicetos com propriedades eliciadores destaca-se Pycnoporus sanguineus (L. ex Fr.) Murr., utilizado desde a medicina popular (21) até controle alternativo de doenças de plantas $(2 ; 3)$, com potencial para a indução de resistência, tornando-se promissor em pesquisas relacionadas.

Em vista do exposto, este trabalho teve como objetivos, investigar o potencial de extratos de micélio de $P$. sanguineus no controle da mancha angular do feijoeiro, através de avaliações da atividade antimicrobiana in vitro contra $P$. griseola, da indução de resistência e ativação de enzimas de resistência como peroxidase, polifenoloxidase, $\beta$-1,3-glucanase e da influencia em processos fisiológicos relacionados ao fornecimento de energia, como proteínas e clorofilas.

\section{MATERIAL E MÉTODOS}

\section{Obtenção e manutenção do patógeno}

O isolado de $P$. griseola foi obtido a partir de lesões de plantas de feijoeiro infectadas naturalmente com a doença e cultivado em meio de suco de tomate $(200 \mathrm{~mL}$ de suco de tomate integral $+15 \mathrm{~g}$ de Agar +

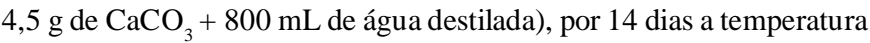
de $24{ }^{\circ} \mathrm{C}$ com escotofase total (23).

\section{Obtenção do extrato aquoso de micélio de $P$. sanguineus}

$P$. sanguineus foi cultivado em meio de cultura sólido (BDA) e posteriormente repicado para meio líquido (BD). Foram utilizados frascos erlenmeyers de $250 \mathrm{~mL}$ contendo $100 \mathrm{~mL}$ de meio $\mathrm{BD}$, autoclavado a $120{ }^{\circ} \mathrm{C}$ e $1 \mathrm{~atm}$ por $20 \mathrm{~min}$. Cada frasco recebeu três discos (5 mm de diâmetro cada) de meio de cultura sólido, contendo micélio do fungo, obtidos de colônias com 14 dias de idade. Após a repicagem os frascos foram mantidos em agitação (150 rpm) sob temperatura de $\pm 26^{\circ} \mathrm{C}$ e luz ambiente por 30 dias de incubação. Após esse período, as colônias foram filtradas separadamente e assepticamente em papel Whatman $\mathrm{n}^{\circ} 41$, obtendo-se dessa forma $\mathrm{o}$ micélio do fungo. O micélio obtido foi seco em estufa a $45^{\circ} \mathrm{C}$ (temperatura que não altera os compostos químicos presentes no micélio) até peso constante e em seguida moído em moinho de esfera. O preparo dos extratos aquosos constituiu na hidratação do pó seco de micélio por $24 \mathrm{~h}$ a temperatura de $4{ }^{\circ} \mathrm{C}$, na proporção de $14 \mathrm{~mL}$ água destilada para $1 \mathrm{~g}$ de pó seco, sendo em seguida filtrados em papel de filtro Whatman $\mathrm{n}^{\circ} 1$, obtendo dessa forma o extrato bruto (8), do qual realizaram-se as diluições posteriores com água.

\section{Inibição de germinação de esporos}

O teste de inibição de germinação de esporo na presença dos extratos foi realizado em lâmina de microscopia revestida por fina camada de ágar-água a $1 \%(700 \mu \mathrm{L}$ por lâmina). Alíquotas de $40 \mu \mathrm{L}$ das concentrações dos extratos aquosos, ajustadas para se obter concentrações finais de $0,1,5,10,15$ e $20 \%$, esterilizados em autoclave ou filtrados em membrana de nitrocelulose $(0,45 \mu \mathrm{m}$ de diâmetro de poro) e alíquotas de $40 \mu \mathrm{L}$ da suspensão de esporos de $P$. griseola $\left(1 \times 10^{4}\right.$ conídios $\left./ \mathrm{mL}\right)$ obtidos de cultura com 14 dias de idade, foram distribuídas na superfície das lâminas, as quais foram incubadas em câmara úmida com escotofase total a $24^{\circ} \mathrm{C}$. Como controles utilizaramse fungicida azoxystrobin (40 mg i.a./L) e acibenzolar-S-metil (ASM: $75 \mathrm{mg}$ i.a./L). A porcentagem de germinação foi determinada 24 horas após a instalação do experimento com a adição de uma alíquota de 40 $\mu \mathrm{L}$ de lactofenol com azul de algodão em cada lâmina, a fim de paralisar a germinação de esporos (22).

\section{Inibição de crescimento micelial e da esporulação}

Os extratos de micélio de $P$. sanguineus foram incorporados nas concentrações de $0,1,5,10,15$ e $20 \%$, em meio de cultura de suco de tomate. Os extratos foram esterilizados em autoclave e também por filtração em membrana de nitrocelulose $(0,45 \mu \mathrm{m}$ de diâmetro de poro). Utilizaram-se como tratamentos controles o fungicida azoxystrobin (40 mg i.a./L) e acibenzolar-S-metil (ASM: $75 \mathrm{mg}$ i.a./L). Para a repicagem de P. griseola nas placas de petri contendo os tratamentos, uma alíquota de $100 \mu \mathrm{L}$ de suspensão de esporo ( $1 \times 10^{4}$ conídios $\left./ \mathrm{mL}\right)$ de cultura com 14 dias de idade foi adicionada nas placas e homogeneizado com alça de Drigalski. As placas foram vedadas com filme plástico e mantidas a $24{ }^{\circ} \mathrm{C}$ com escotofase total. As avaliações realizaram-se por meio de medições do diâmetro e número de colônias 14 dias após a instalação do experimento. Ao término do teste de inibição do crescimento micelial, avaliou-se a esporulação de cada uma destas placas. Para isto, preparou-se uma suspensão de esporos através da adição de $10 \mathrm{~mL}$ de água destilada por placa, raspagem da colônia e filtragem em gaze, sendo determinado o número de esporos por $\mathrm{mL}$ em câmara de Neubauer ao microscópio óptico.

\section{Cultivo e aplicação dos tratamentos em casa de vegetação}

Plantas de feijoeiro (IAPAR 81 - Carioca) foram cultivadas em vasos plásticos (duas plantas/vaso) contendo uma mistura de solo e areia esterilizados (proporção 2:1). Não realizou-se adubação devido a análise de solo apresentar resultados satisfatórios de nutrientes. Para o teste de indução de resistência, utilizaram-se os tratamentos com extratos aquosos de micélio de P. sanguineus, nas concentrações 10 e $20 \%$, e os controles água, fungicida sistêmico azoxystrobin (40 $\mathrm{mg}$ i.a./L) e acibenzolar-S-metil (75 mg i.a./L). Os tratamentos foram aplicados por aspersão na $3^{\mathrm{a}}$ folha (V4), em quantidades de $3 \mathrm{~mL}$ por folha.

\section{Cultivo e aplicação dos tratamentos a campo}

$\mathrm{O}$ experimento constituiu-se de três blocos casualizados, sendo que cada bloco era composto por cinco parcelas, e cada parcela dentro de um bloco representava um tratamento, totalizando cinco tratamentos. Cada parcela tinha três linhas de $3 \mathrm{~m}$ de comprimento, espaçadas 0,5 $\mathrm{m}$ entre si, com dez plantas (IAPAR 81 - Carioca) viáveis por metro linear. A linha central, descontando-se $0,5 \mathrm{~m}$ da bordadura anterior e posterior, foi considerada área útil para avaliação. Foram aplicados 400 kg/ha de NPK (04-14-08) no sulco da semeadura (de acordo com análise de solo) e os demais tratos culturais como capinas foram realizados sempre que necessário. Para o teste de indução de resistência a campo, utilizaram-se os tratamentos com extratos aquosos de micélio de $P$. sanguineus, nas concentrações 10 e $20 \%$, além dos controles água, fungicida sistêmico azoxystrobin (40 mg i.a./L) e acibenzolar-Smetil (75 $\mathrm{mg}$ i.a./L).

Os extratos foram aplicados por aspersão em toda a planta $(5 \mathrm{~mL}$ de solução por planta). Divididas em duas aplicações: a primeira na fase vegetativa (V3) e a segunda na fase reprodutiva (R3).

\section{Inoculação do patógeno}

A suspensão de esporos do fungo $P$. griseola foi preparada em água com Tween 20 (uma gota/500 mL), sendo a concentração ajustada para $4 \times 10^{4}$ conídios $/ \mathrm{mL}$. A inoculação em casa de vegetação foi realizada por aspersão três dias após a aplicação dos tratamentos, na $3^{\mathrm{a}}$ folha trifoliolada tratada bem como na $4^{\mathrm{a}}$ folha trifoliolada não tratada (fase vegetativa V4). Após a inoculação, as plantas foram mantidas em 
câmara-úmida e no escuro a temperatura ambiente por $48 \mathrm{~h}$ e, posteriormente, mantidas em casa de vegetação, segundo metodologia utilizada por Stangarlin et al. (23). A campo realizaram-se duas inoculações por aspersão da suspensão de esporos $\left(4 \times 10^{4}\right.$ conídios/ $\mathrm{mL}$ ), sendo a primeira na fase vegetativa (V3) e a segunda na fase reprodutiva (R3), ambas três dias após aplicação dos tratamentos.

\section{Avaliação de severidade}

A severidade da doença em casa de vegetação foi avaliada nas $3^{\mathrm{a}} \mathrm{e}$ $4^{\text {a }}$ folhas aos 8, 12, 16, 20 e 24 dias após a inoculação, com escala diagramática elaborada por Godoy et al. (14). A campo as avaliações iniciaram quando surgiu o primeiro sintoma da doença, e obtendo-se cinco avaliações a cada quatro dias da porção mediana inferior das plantas. Na segunda aplicação dos tratamentos, a severidade foi avaliada da mesma forma que na primeira aplicação, porém avaliandose a porção mediana superior do feijoeiro. Com as avaliações de severidade da doença, procedeu-se a construção da curva de progresso da doença e a determinação da área abaixo da curva de progresso da doença (AACPD) por meio de equação proposta por Campbell \& Madden (6).

\section{Coleta de amostras para análises bioquímicas}

Discos de folha com $3,46 \mathrm{~cm}^{2}$ (três discos/amostra) foram coletados $48,72,96$ e 120 h após a inoculação e também quando do aparecimento dos sintomas. Durante o procedimento, cada amostra coletada foi imediatamente acondicionada em envelopes de papel alumínio e congelada a $-20{ }^{\circ} \mathrm{C}$. Coletaram-se amostras nas $3^{\text {as }}$ folhas trifoliadas inoculadas, bem como nas $4^{\text {as }}$ folhas trifoliadas não-inoculadas (24).

\section{Obtenção dos extratos protéicos}

As amostras de folhas foram homogeneizadas mecanicamente em $2 \mathrm{~mL}$ de tampão fosfato de sódio $0,01 \mathrm{M}$ (pH 6,0) (tampão de extração), em almofariz de porcelana. O homogenato foi centrifugado a $6.500 \mathrm{~g}$ durante 10 min a $4{ }^{\circ} \mathrm{C}$, sendo o sobrenadante obtido considerado como extrato enzimático, para posterior determinação da atividade de peroxidase, polifenoloxidase, $\beta$-1,3-glucanase e conteúdo protéico.

\section{Atividade de peroxidase}

A atividade de peroxidases foi determinada a $30^{\circ} \mathrm{C}$, através de método espectrofotométrico direto a $470 \mathrm{~nm}$ durante $2,15 \mathrm{~min}$ (18). A atividade da peroxidase foi expressa em absorbância/min/g de peso fresco.

\section{Atividade de polifenoloxidase}

A atividade de polifenoloxidase foi determinada de acordo com a metodologia de Duangmal \& Apenten (10). Os resultados foram expressos em absorbância/min/g peso fresco.

\section{Atividade de $\beta$-1,3-glucanase}

A atividade da $\beta$-1,3-glucanase foi avaliada segundo metodologia descrita por Stangarlin et al. (23). A reação foi determinada pela quantificação colorimétrica de glicose liberada da laminarina, através do uso da hidrazida do ácido $p$-hidroxibenzóico (HAPHB). As leituras de absorbância foram plotadas em curva padrão para glicose e os resultados expressos em $\mathrm{mg}$ de glicose/min/g peso fresco.

\section{Teor de proteína}

O teor de proteínas totais foi avaliado pelo método de Bradford (5). A concentração de proteínas, expressa em termos equivalentes de $\mu \mathrm{g}$ de albumina de soro bovino (ASB) em um $\mathrm{mL}$ de amostra $(\mu \mathrm{g}$
proteína/mL), foi determinada utilizando-se curva padrão de concentrações de ASB, variando de 0 a $20 \mu \mathrm{g} / \mathrm{mL}$.

\section{Teor de clorofila}

Para a quantificação da clorofila foi utilizada a metodologia adaptada de Arnon (1). As amostras de tecido vegetal (0,100 g) foram acondicionadas em frascos de vidro com $10 \mathrm{~mL}$ de acetona $80 \%$, durante 7 dias. Após esse período realizou-se leitura no espectrofotômetro a $663 \mathrm{~nm}$ e $645 \mathrm{~nm}$ para clorofila $a$ e $b$, respectivamente. A concentração de clorofila $a$ obteve-se pela fórmula $\left(0,0127 . \mathrm{A}_{663}\right)-\left(0,00269 . \mathrm{A}_{645}\right)$ e para clorofila $b$ pela fórmula $\left(0,0229 \cdot A_{645}\right)-\left(0,00468 \cdot A_{663}\right)$. O teor de clorofila total foi obtido pela soma dos resultados. Os valores foram expressos em $\mathrm{mg} / \mathrm{g}$ peso fresco.

\section{RESULTADOS E DISCUSSÃO}

\section{Atividade antimicrobiana in vitro}

A análise de variância do efeito das concentrações do extrato de micélio de $P$. sanguineus sobre a germinação, crescimento micelial e esporulação de $P$. griseola foi significativa apenas para o extrato esterilizado por filtração (Figura 1), não apresentando diferença estatística para o extrato autoclavado (dados não mostrados). Isto indica a presença de compostos termolabeis no micélio de $P$. sanguineus.

A germinação de esporos foi reduzida em até $70 \%$ na concentração $20 \%$ em relação ao ASM. A mesma concentração reduziu totalmente o crescimento micelial e a esporulação em $100 \%$ a partir da concentração $5 \%$, não diferindo estatisticamente do fungicida, e as concentrações 5, 10 e $15 \%$ foram tão fungitóxicas quanto o ASM.

A atividade antimicrobiana de extratos basidiocarpos também tem sido constatada em outros trabalhos. Extratos dos cogumelos Lentinula edodes (Berk) Pegler e Agaricus blazei (Murrill) ss. Heinem em concentrações variando de 100 a $40.000 \mu \mathrm{g} / \mathrm{mL}$ inibiram a germinação de esporos de Puccinia recondida Rob ex desm. f.sp. tritici, embora não tenham apresentado efeito sobre o crescimento micelial e a germinação de esporos de Bipolaris sorokiniana (Sacc. In Sorok) Schoem (12).

Entre os basidiomicetos, a família Polyporaceae tem sido a mais estudada, sendo que aproximadamente $75 \%$ de suas espécies apresentam grande atividade antimicrobiana. Numerosos componentes desses fungos, como polissacarídeos derivados da parede celular, apresentam atividade antiviral, citotóxica e/ou anti-neoplásica, o que tem atraído a atenção de pesquisadores (25).

\section{Avaliação da severidade em casa de vegetação e campo}

De acordo com a área abaixo da curva de progresso da doença (AACPD) em casa de vegetação e a campo (Tabela 1), verifica-se que as plantas tratadas com o extrato de $P$. sanguineus diferiram da água com reduções na severidade em até 81 e $93 \%$ na $3^{a}$ e $4^{a}$ folha, respectivamente. A campo, na porção mediana inferior, verificou-se diferença estatística, com AACPD superior nos tratamentos quando comparados ao fungicida, não diferindo da água e do ASM. Efeito contrário se verificou na porção mediana superior para a $2^{\mathrm{a}}$ aplicação, onde os tratamentos com extrato de micélio apresentaram reduções significativas da AACPD quando comparados com a água, com reduções de até $50 \%$ para o tratamento com micélio $20 \%$, que apresentou valor inferior ao indutor de resistência comercial (ASM). Quando comparados ao fungicida, os tratamentos diferiram do mesmo, apresentando maior severidade. 

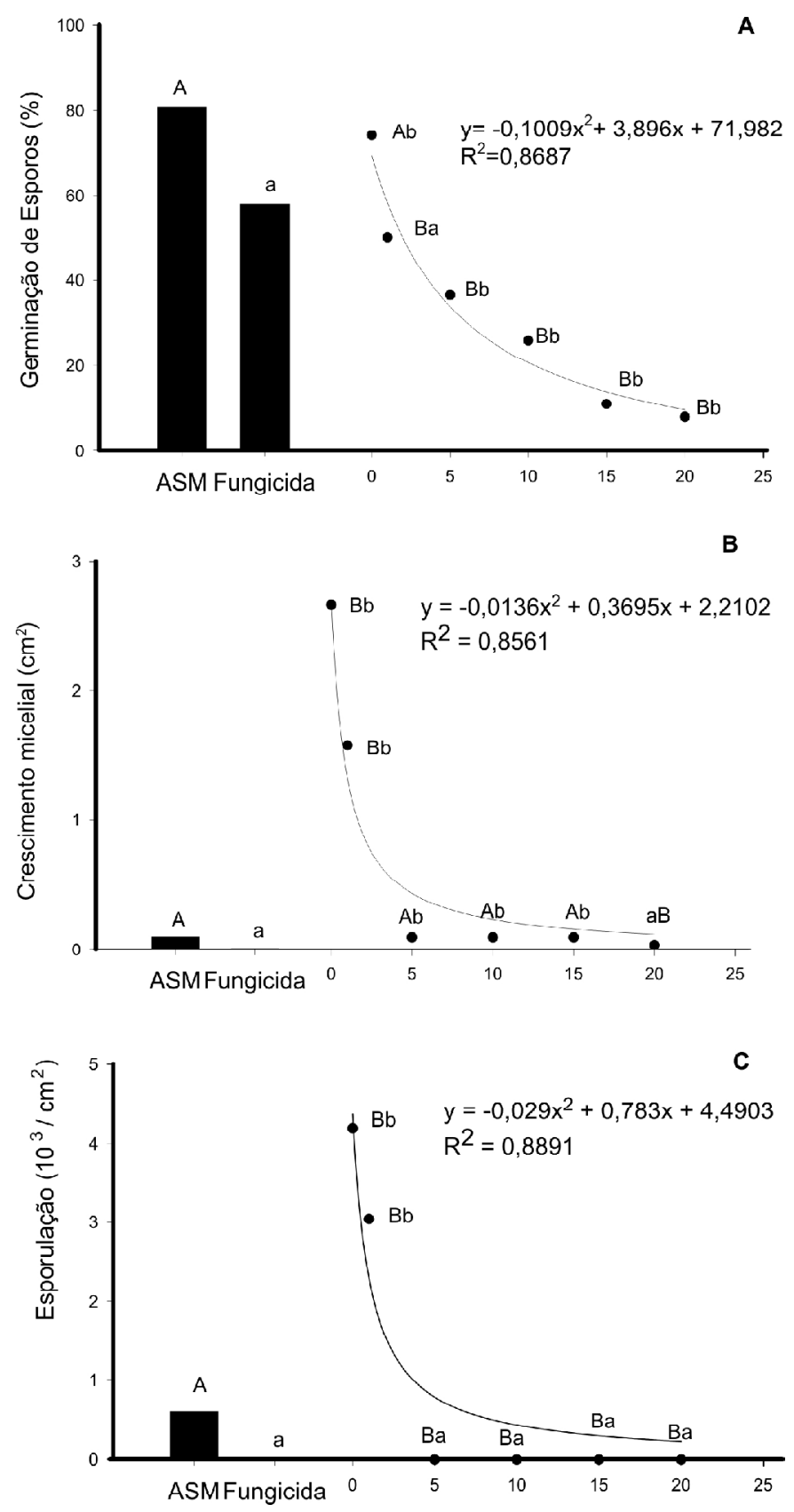

Figura 1. Inibição in vitro da germinação de esporos (a), crescimento micelial (b) e esporulação (c) de P. griseola em função do tratamento com extrato aquoso de micélio de $P$. sanguineus, esterilizado por filtração. Médias seguidas de mesma letra (maiúscula para comparação com ASM e minúscula para comparação com Fungicida) não diferem estatisticamente pelo teste de Dunnett's a 5\% de probabilidade. Dados do ensaio de germinação de esporos transformados por $\sqrt{ } \mathrm{x}+0,5$. ASM: acibenzolar-Smetil (75 mg i.a./L). Fungicida azoxystrobin (40 mg i.a./L).

Assi (2) obteve resultados semelhantes com extrato aquoso de $P$. sanguineus, reduzindo a severidade da antracnose em feijoeiro de forma sistêmica. Di Piero \& Pascholati (8) demonstraram redução parcial na severidade de antracnose em folhas de pepino pré-tratadas com os extratos de Lentinula edodes e Agaricus blazei, de forma sistêmica. $\mathrm{O}$ efeito protetor foi dependente da concentração de cogumelo utilizada e, em menor grau, do intervalo de tempo entre a indução e a inoculação e o ambiente.
Tabela 1. Área abaixo da curva de progresso da doença (AACPD) para mancha angular causada por $P$. griseola em feijoeiro em função dos tratamentos com extratos aquosos de micélio de $P$. sanguineus, em condições de casa de vegetação e campo.

\begin{tabular}{lllll}
\hline \multirow{2}{*}{ Tratamentos } & \multicolumn{4}{c}{ AACPD } \\
\cline { 2 - 5 } & \multicolumn{2}{c}{ Casa de vegetação } & \multicolumn{2}{c}{ Campo } \\
& $\mathbf{3}^{\text {a }}$ folha & $\mathbf{4}^{\mathbf{a}}$ folha & P.M.I & P.M.S \\
\hline Micélio $10 \%$ & $8,1^{1}$ & $3,1^{1}$ & $57,7^{3}$ & $68^{1,3}$ \\
Micélio $20 \%$ & $9,6^{1,2}$ & $4,1^{1}$ & $48,6^{3}$ & $44,2^{1,2,3}$ \\
Água & 41,9 & 8,8 & 59,4 & 89 \\
ASM $^{*}$ & 2,3 & 5,2 & 41,9 & 67,7 \\
Fungicida $^{* *}$ & 6,7 & 2,4 & 6,3 & 16,1 \\
\hline C.V. (\%) & 31 & 7,3 & 47,5 & 53,9 \\
\hline
\end{tabular}

Médias na coluna, seguida de número indica diferença estatística a $5 \%$ pelo teste de Dunnett's quando comparada aos controles água (1), ASM (2) e Fungicida (3). Para análise estatística os dados foram transformados por " $x+0,5$;

ASM: acibenzolar-S-metil (75 mg i.a./L);

** Fungicida: azoxystrobin (40 mg i.a./L);

P.M.I: Porção mediana inferior da planta;

P.M.S: Porção mediana superior da planta.

\section{Atividade de peroxidase}

A atividade de peroxidase apresentou-se alterada nas plantas tratadas com extrato de micélio de P. sanguineus (Figura 2). O extrato aquoso a $10 \%$ reduziu a atividade de peroxidase aos 3, 5 e 7 dias após a inoculação (DAI), quando comparados ao ASM e fungicida. Por outro lado, o tratamento com micélio $20 \%$ apresentou-se superior quando comparado ao ASM e fungicida (2 DAI), à água e ao fungicida (3 DAI) e ao fungicida (4 DAI). Reduções comparadas com à água e ao ASM foram verificadas a partir dos 5 DAI. A $4^{\text {a }}$ folha não tratada apresentou os mesmos efeitos que a $3^{\mathrm{a}}$ folha sobre a atividade da peroxidase, indicando um provável efeito indutor sistêmico.

Mudanças na atividade das peroxidases têm sido freqüentemente correlacionadas a resposta de resistência ou suscetibilidade em diferentes patossistemas. As peroxidases são responsáveis pela remoção de átomos de hidrogênio dos grupos álcoois hidroxicinâmicos, cujos radicais se polimerizam para formar a lignina. Esse polímero, juntamente com celulose e outros polissacarídeos que ocorrem na parede celular das plantas superiores, funciona como uma barreira física à penetração do patógeno (7).

\section{Atividade de polifenoloxidase}

A atividade da polifenoloxidase foi influenciada pelos tratamentos com extratos de micélio de $P$. sanguineus, na $3^{\text {a }}$ folha tratada, bem como na $4^{\text {a }}$ folha não tratada e inoculada, demonstrando a sistemicidade do efeito (Figura 2). O extrato aquoso de micélio a $10 \%$ reduziu a atividade enzimática aos 3, 5 e 7 DAI, quando comparados ao ASM, ASM e fungicida e ASM respectivamente, porém, foi maior que a água e o fungicida aos 4 DAI. O tratamento com micélio $20 \%$ apresentouse superior quando comparado ao fungicida (3 DAI) e à água e ao fungicida (4 e 5 DAI), apresentando redução na atividade enzimática em relação ao ASM, quando do aparecimento do sintoma (7 DAI).

\section{Atividade de $\beta$-1,3-glucanase}

A atividade da $\beta$-1,3-glucanase foi influenciada pelos tratamentos com extratos de $P$. sanguineus, na $3^{\mathrm{a}}$ folha tratada, bem como na $4^{\mathrm{a}}$ folha não tratada e inoculada, comprovando a sistemicidade do efeito também para essa enzima, como já observado em peroxidase e polifenoloxidase (Figura 2). O micélio a 10\%, em relação a água, estimulou aos 3 DAI e inibiu aos 5 DAI a atividade enzimática, enquanto que o extrato a $20 \%$ inibiu a atividade da $\beta-1,3$-glucanase 
(a)

\section{Peroxidase}

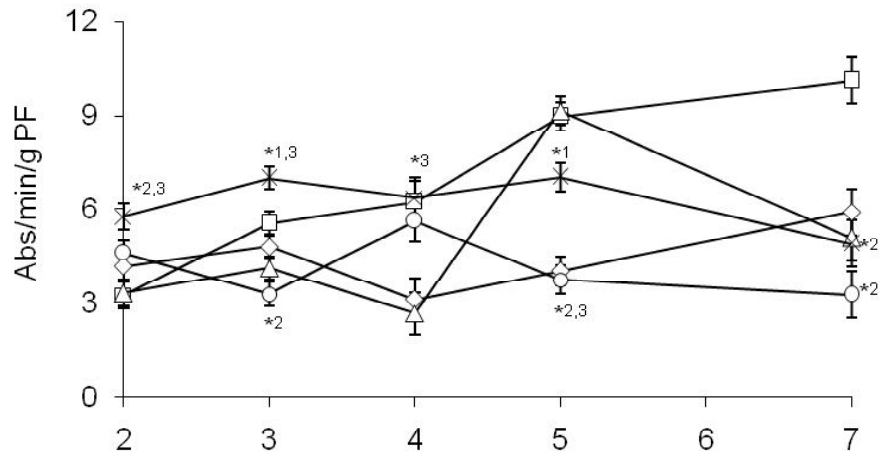

Polifenoloxidase

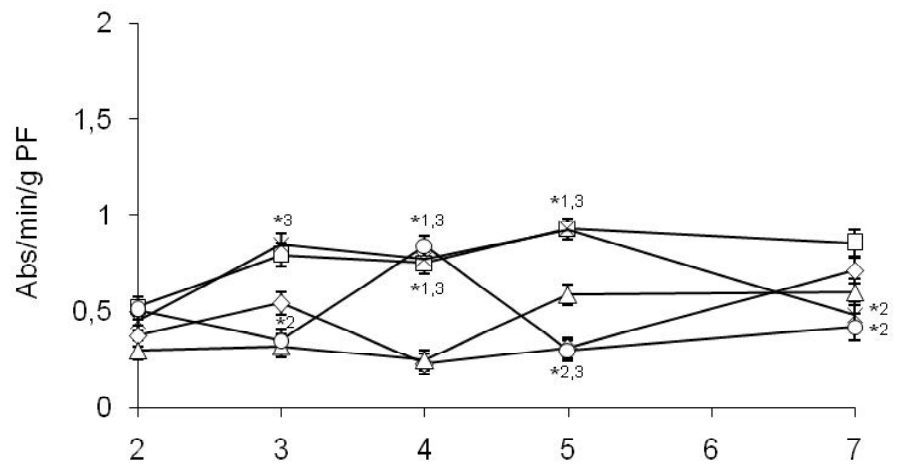

\section{及-1,3-glucanase}

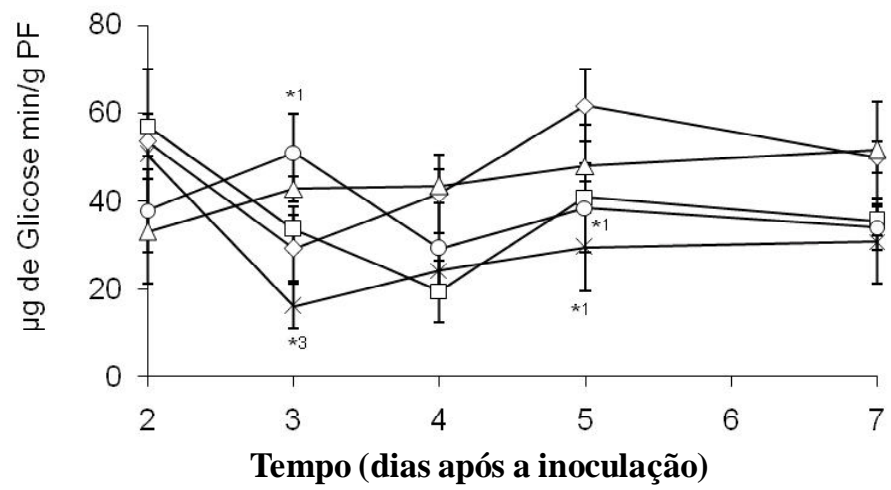

(b)
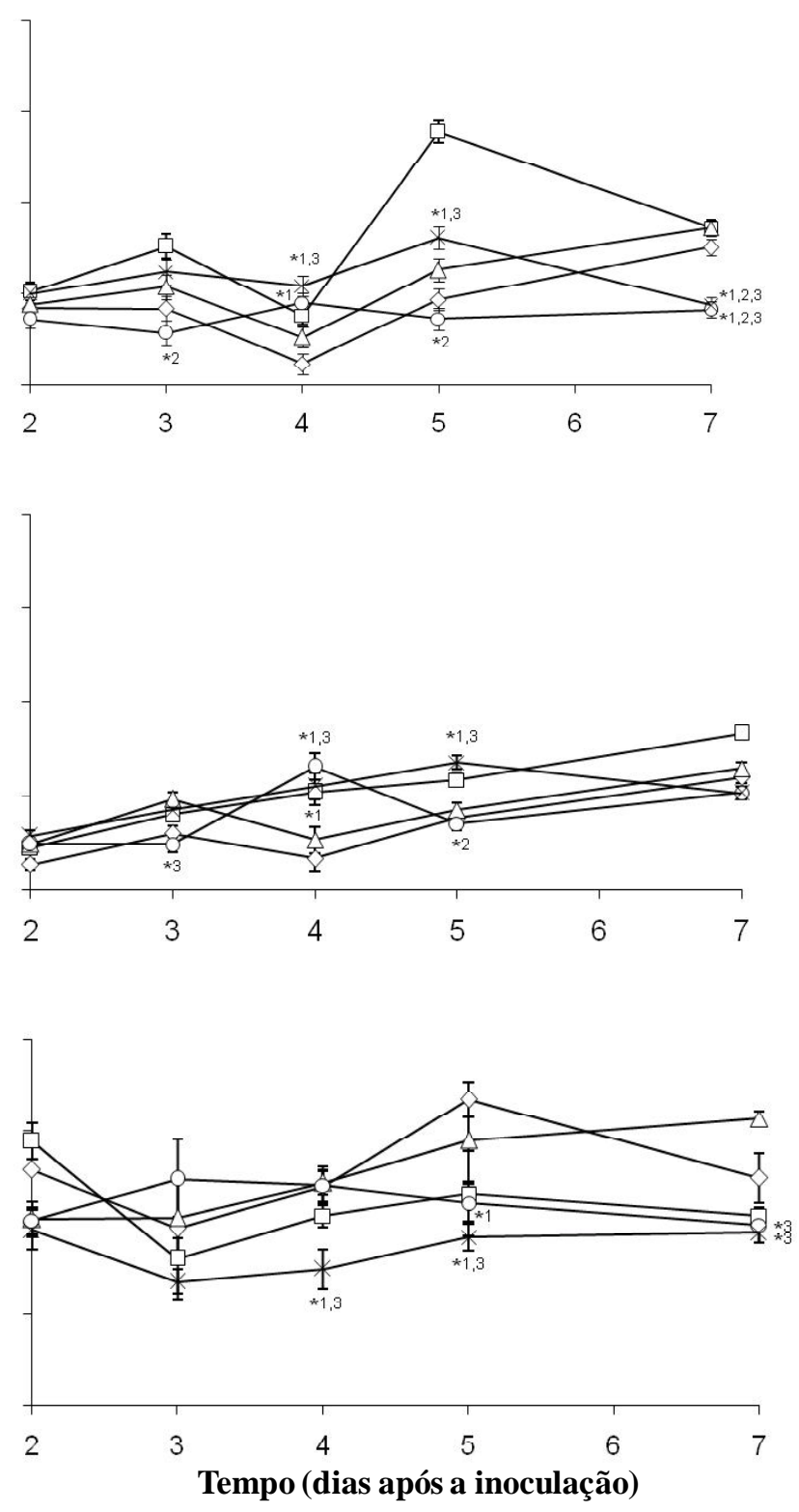

Figura 2. Atividade de peroxidase, polifenoloxidase e $\beta-1,3$-glucanase em plantas de feijoeiro inoculadas com P. griseola três dias após os tratamentos com os controles $(\diamond)$ água, $(\square)$ Acibenzolar-S-metil (ASM $75 \mathrm{mg}$ i.a./L) e $(\triangle)$ Fungicida azoxystrobin $(40 \mathrm{mg}$ i.a./L) e os extratos aquosos de micélio de P. sanguineus a $10 \%$ e $20 \%$ (O e $\times$ ). (a) e (b) representam respectivamente a $3^{\mathrm{a}}$ folha tratada e inoculada e a $4^{\mathrm{a}}$ folha apenas inoculada. Barras indicam a média \pm o erro padrão. (*) Seguido de número indica diferença estatística a 5\% pelo teste de Dunnett's quando comparada aos controles (1) água, (2) ASM e (3) Fungicida. PF: peso fresco.

aos 3 DAI, em comparação ao fungicida, e aos 5 DAI em relação a água. A $4^{\mathrm{a}}$ folha não tratada apresentou efeitos semelhantes a $3^{\mathrm{a}}$ folha sobre a atividade da $\beta$-1,3-glucanase, de forma ainda mais acentuada.

De acordo com Stangarlin et al. (23), plantas de feijoeiro desafiadas com o hemibiotrófico $P$. griseola não alteraram a atividade de $\beta$-1,3-glucanase, ao passo que, quando desafiadas com o fungo biotrófico Uromyces appendiculatus, a indução da atividade de $\beta$ 1,3-glucanase foi verificada (24). Dessa forma, supõe-se que existe uma relação entre o tratamento eliciador e o patógeno desafiante, na ativação dos mecanismos de defesa em plantas. A planta poderia investir em compostos que normalmente ela ativaria na presença do patógeno, porém, com maior eficiência quando pré-disposta a um eliciador.

\section{Teor de proteína}

O teor de proteína foi significativamente alterado tanto na folha tratada como na folha não tratada com os extratos de $P$. sanguineus. $\mathrm{O}$ extrato de micélio estimulou a síntese protéica aos 4 DAI comparado aos três controles, e aos 5 e 7 DAI em relação a água e fungicida e a água, respectivamente. $\mathrm{O}$ extrato a $20 \%$ foi superior à água e ao fungicida (3 DAI), aos três controles (4 DAI), à água e ASM (5 DAI) e a água (7 DAI). (Figura 3).

O conteúdo de proteínas no tecido vegetal desafiado com um patógeno ou tratado com eliciador indica a ativação dos mecanismos de defesa $(23,24)$. A síntese de proteínas poderia estar relacionada com o aumento da demanda de substrato de plantas com resistência induzida por $P$. sanguineus. Entre as proteínas, há as relacionadas à 
(a)

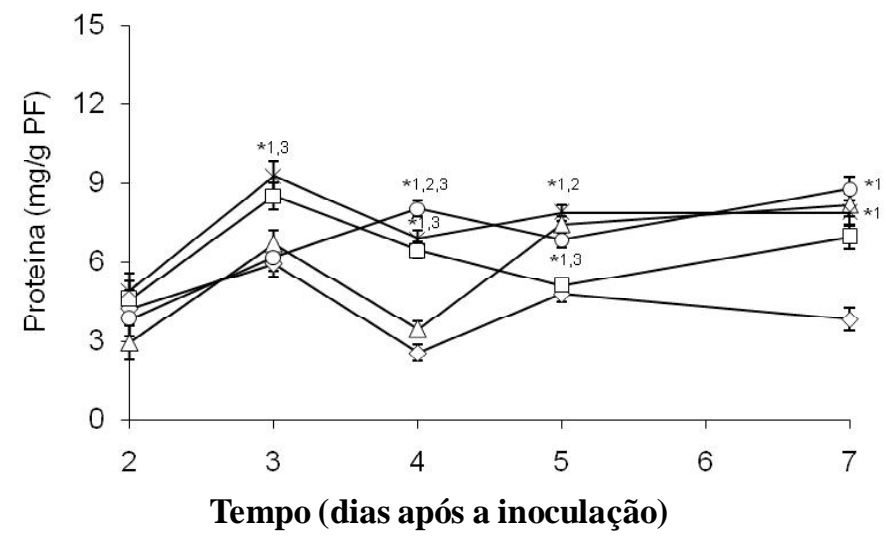

(b)

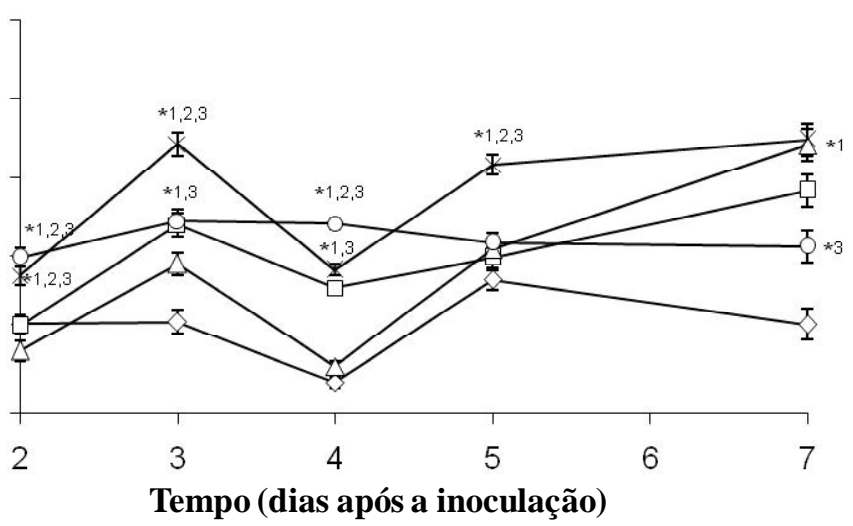

Figura 3. Teor de proteína em plantas de feijoeiro inoculadas com Pseudocercospora griseola três dias após os tratamentos com os controles $(\diamond)$ água, ( $\square$ ) Acibenzolar-S-metil (ASM $75 \mathrm{mg}$ i.a./L) e $(\triangle$ ) Fungicida azoxystrobin (40 mg i.a./L) e os extratos aquosos de micélio de Pycnoporus sanguineus a 10\% e $20 \%(\mathrm{O}$ e $\times)$. (a) e (b) representam respectivamente a $3^{\mathrm{a}}$ folha tratada e inoculada e a $4^{\mathrm{a}}$ folha apenas inoculada. Barras indicam a média \pm o erro padrão. (*) Seguido de número indica diferença estatística a 5\% pelo teste de Dunnett's quando comparada aos controles (1) água, (2) ASM e (3) Fungicida. PF: peso fresco.
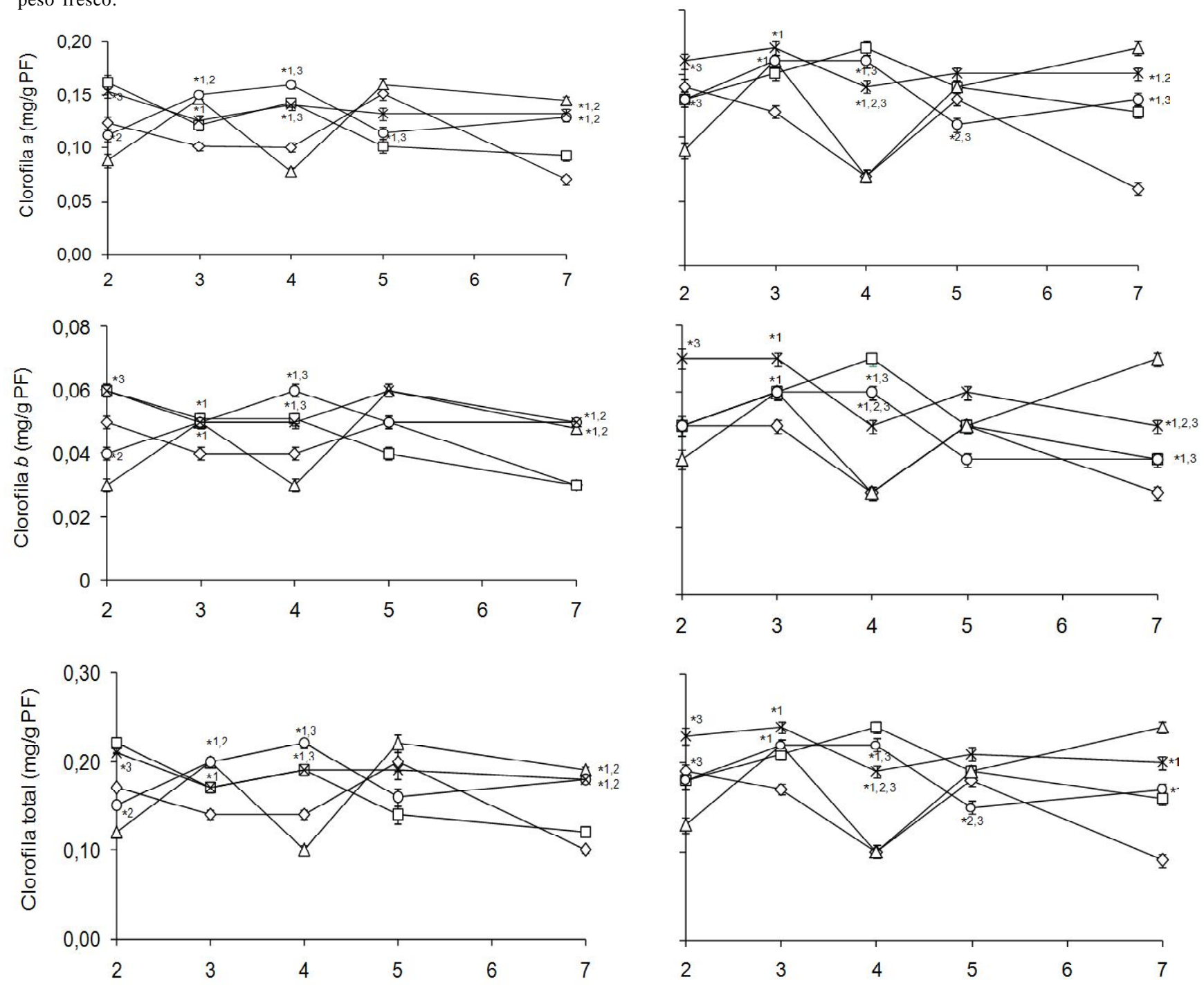

Figura 4. Teor de clorofila $a, b$ e total em plantas de feijoeiro inoculadas com Pseudocercospora griseola três dias após os tratamentos com os controles $(\diamond)$ água, $(\square)$ Acibenzolar-S-metil (ASM $75 \mathrm{mg}$ i.a./L) e $(\triangle)$ Fungicida azoxystrobin $(40 \mathrm{mg}$ i.a./L) e os extratos aquosos de micélio de Pycnoporus sanguineus a $10 \%$ e $20 \%(\mathrm{O}$ e $\times)$. (a) e (b) representam respectivamente a $3^{\mathrm{a}}$ folha tratada e inoculada e a $4^{\mathrm{a}}$ folha apenas inoculada. Barras indicam a média \pm o erro padrão. (*) Seguido de número indica diferença estatística a 5\% pelo teste de Dunnett’s quando comparada aos controles (1) água, (2) ASM e (3) Fungicida. PF: peso fresco. 
patogênese (Proteínas-RP), as quais são induzidas nos tecidos vegetais em função da inoculação com patógenos/microrganismos, sistemicamente ou em parte destes, bem como pelo tratamento com agentes químicos (15). A ativação da síntese protéica leva a uma fase de resistência da planta (17). Kuhn (16) verificou redução no teor de proteínas em plantas de feijão quando tratadas com Bacillus cereus, tendência contrária ao tratamento com acibenzolar-S-metil, demonstrando a especificidade na resposta fisiológica deste hospedeiro ao tratamento.

\section{Teor de clorofila}

O conteúdo de clorofila $a, b$ e total em plantas de feijoeiro tratadas com os extratos aquosos de $P$. sanguineus e desafiadas com $P$. griseola mostraram-se alteradas na $3^{\text {a }}$ folha tratada bem como na $4^{\text {a }}$ folha apenas inoculada (Figura 4). O micélio 10\% reduziu o teor de total de clorofila aos 2 DAI, em relação ao ASM. Porém, aumentos significativos são verificados em comparação com a água (3, 4 e 7 DAI), ao ASM (3 e 7 DAI) e ao fungicida (4 DAI). O micélio a $20 \%$ apresentou resultados superiores a água (3, 4 e 7 DAI), ao ASM (7 DAI) e ao fungicida (2 e 4 DAI).

Esses resultados sugerem a necessidade de produção de energia para síntese dos compostos de defesa da planta, considerando-se que as moléculas de clorofila $a$ e $b$ constituem os dois sistemas de pigmentos responsáveis pela absorção e transferência de energia radiante (11). A energia gerada pelo processo de fotossíntese pode, em dado momento, estar voltada para a produção de compostos do metabolismo secundário, como por exemplo, no caso de ataque de patógenos (17).

Fungos hemibiotróficos como $P$. griseola podem implicar diretamente no grau das alterações do hospedeiro, quer seja em nível de fotossíntese, quer seja em nível de respostas de defesa frente à infecção (23).

Diante dos resultados aqui apresentados pode-se concluir que os extratos obtidos de micélio de $P$. sanguineus controlaram a mancha angular do feijoeiro causada por $P$. griseola, por meio de atividade antimicrobiana in vitro, inibindo a germinação de esporos, crescimento micelial e espoulação do patógeno, como pela indução de enzimas de defesa como peroxidase e polifenoloxidase. Alterações fisiológicas como o teor de proteínas e clorofilas foram alteradas acentuadamente nas plantas de feijoeiro tratadas com os extratos de $P$. sanguineus, indicando sua eficiência para esse patossistema.

\section{AGRADECIMENTOS}

Os autores agradecem a Fundação Araucária e à FINEP pelo apoio financeiro na execução do projeto. JRS e KRFSE agradecem ao CNPq pela bolsa de produtividade em pesquisa.

\section{REFERÊNCIAS BIBLIOGRÁFICAS}

1. Arnon, D.I. Copper enzymes in isolated chloroplasts. Polyphenoloxidase in beta vulgaris. Plant Physiology, Rockville, v. 24, p. 1-15, 1949.

2. Assi, L. Controle de Colletotrichum lindemuthianum (Sacc. Et Magn.) Scrib, na cultura do feijão (Phaseolus vulgaris L.) pelo extrato do cogumelo Pycnoporus sanguineus (L. ex. Fr.). 2005, 51p. Dissertação (Mestrado em agronomia) Universidade Estadual do Oeste do Paraná, Marechal Cândido Rondon.

3. Beninca, C.P. Indução de fitoalexinas e atividade de peroxidases em sorgo e soja tratados com extratos de basidiocarpos de Pycnoporus sanguineus. 2007, 45p. Dissertação (Mestrado em agronomia) Universidade Estadual do Oeste do Paraná,
Marechal Cândido Rondon.

4. Bianchini, A.; Maringoni, A. C.; Carneiro, S. M. T. P. G. Doenças do feijoeiro. In: Kimati, H.; Amorim, L.; Bergamin Filho, A.; Camargo, L. E. A.; Rezende, J. A. M. (Eds.). Manual de fitopatologia: Doenças das plantas cultivadas. 4.ed. São Paulo: Ceres, 2005. v.2, p. 333-349.

5. Bradford, M.M. A rapid and sensitive method for the quantification of microgram quantities of protein utilizing the principle of protein-dye binding. Analytical Biochemistry, New York, v. 72, p. 248-254, 1976.

6. Campbell, C.L.; Madden, L.V. Introduction to plant disease epidemiology. New York: John Wiley, 1990, 532p.

7. Cavalcanti, L.S.; Brunelli, K.R.; Stangarlin, J.R. Aspectos bioquímicos e moleculares da resistência induzida. In: Cavalcanti, L.S.; Di Piero, R.M.; Cia, P.; Pascholati, S.F.; Resende, M.L.V.; Romeiro, R.S. (Eds.). Indução de resistência em plantas a patógenos e insetos. Piracicaba: FEALQ, 2005, p. 81-124.

8. Di Piero, M.R.; Pascholati, S.F. Indução de resistência em plantas de pepino contra Colletoptrichum lagenarium pela aplicação de extratos de basidiocarpos de Lentinula edodes e de Agaricus blazei. Summa Phytophatologica, Botucatu, v. 30, p. 243-250, 2004.

9. Di Piero, R.M.; Garcia Jr.D.; Tonucci, N.M. Indutores bióticos. In: Cavalcanti, L.S.; Di Piero, R.M.; Cia, P.; Pascholati, S.F.; Resende, M.L.V.; Romeiro, R.S. (Ed.). Indução de resistência em plantas a patógenos e insetos. Piracicaba: FEALQ, 2005, p. 29-50.

10. Duangmal, K.; Apenten, R.K.O. A comparative study of polyphenoloxidases from taro (Colocasia esculenta) and potato (Solanun tuberosum var. Romano). Food Chemistry, London, v. 64 , p. 351-359, 1999.

11. Ferri, M.G. Fisiologia vegetal. 2.ed. São Paulo: Editora EPU, 2004, 362p.

12. Fiori-Tutida, A.C.G.; Schwan-Estrada, K.R.F.; Stangarlin, J.R.; Pascholati, S.F. Extratos de Lentinula edodes e Agaricus blazei sobre Bipolaris sorokiniana e Puccinia recondita f.sp. tritici, in vitro. Summa Phytopatologica, Botucatu, v. 33, n. 3, p. 113 118,2007

13. Ghini, R.; Kimati, H. Resistência de fungos a fungicidas Jaguariúna, SP: Embrapa Meio Ambiente, 2000. 78p.

14. Godoy, C.V.; Carneiro, S.M.T.P.G; Iamauti, M.T.; Dalla Pria, M.; Amorim, L.; Berger, R.D.; Bergamin Filho, A. Diagrammatic scales dor bean diseases: development and validation. Zeitschrift fur Pflanzenkrankheiten und Pflanzenschutz, Stutgart, v. 104, n. 4, p. 336-345, 1997.

15. Guzzo, S.D. Proteínas relacionadas à patogênese. In: Luz, W.C. (Ed.) Revisão Anual de Patologias de Plantas, Passo Fundo, v. 11, p. 283-332, 2003.

16. Kuhn, O.J. Indução de resistência em feijoeiro (Phaseolus vulgaris) por acibenzolar-S-metil e Bacillus cereus: aspectos fisiológicos, bioquímicos e parâmetros de produção. 2007 140p. Tese (doutorado em agronomia) Escola Superior de Agricultura "Luiz de Queiroz", USP, Piracicaba.

17. Larcher, W. Ecofisiologia Vegetal. São Carlos: RiMa, 2000 $534 \mathrm{p}$.

18. Lusso, M.F.G.; Pascholati, S.F. Achtivty and isoenzymatic pattern of soluble peroxidases in maise tissues after mechanical injury or fungal inoculation. Summa Phytopathological, Botucatu, v. 25, p. 244-249, 1999.

19. Schwan-Estrada, K.R.F.; Stangarlin, J.R. Extratos de óleos essenciais de plantas medicinais na indução de resistência. In: Cavalcanti, L.S.; Di Piero, R.M.; Cia, P.; Pascholati, S.F.; Resende, M.L.V.; Romeiro, R.S. (Ed.). Indução de resistência em plantas a patógenos e insetos. Piracicaba: FEALQ, 2005. p. $125-$ 138.

20. Schwan-Estrada, K.R.F.; Stangarlin, J.R.; Cruz, M.E.S. Uso de plantas medicinais no controle de doenças de plantas. Fitopatologia Brasileira, Brasília, v. 8, p. 54-56, 2003.

21. Smânia, A.; Monache F.D.; Smania E.F.; Gil M.L.; Benchetrit L.C.; Cruz F.S. Antibacterial activity of a substance produced by the fungus Pycnoporus sanguineus. Journal of Ethnopharma- 
cology, Leiden, v. 45, p. 177-181, 1995.

22. Stangarlin, J.R.; Schwan-Estrada, K.R.F.; Cruz, M. E. S.; Nozaki, M.H. Plantas medicinais e controle alternativo de fitopatógenos. Biotecnologia Ciência \& Desenvolvimento, Brasília, v. 2, n. 11, p. 16-21, 1999.

23. Stangarlin, J.R., Pascholati, S.F; Labate, C; A. Efeito de Phaeoisariopsis griseola na atividade de ribulose-1,5-bifosfato carboxilase-oxigenase (rubisco), clorofilase, $\beta$-1,3-glucanase e quitinase em cultivares de Phaseolus vulgaris. Fitopatologia Brasileira,
Brasília, v. 24, p. 59-66, 2000.

24. Stangarlin, J.R.; Pascholati, S.F. Atividades de ribulose-1,5-bifosfato carboxilase-oxigenase (rubisco), clorofilase, $\beta-1,3$ glucanase e quitinase e conteúdo de clorofila em cultivares de feijoeiro (Phaseolus vulgaris) infectados com Uromyces appendiculatus. Summa Phytopathologica, Botucatu, v. 26, n. 1, p. 34-42, 2000.

25. Wasser, S.P. Medicinal mushrooms as a source of antitumor and immodumonulating polysaccharides. Applied Microbiology and Biotechnology, Heidelberg, v. 60, n. 3, p. 258-274, 2002. 